\title{
Relationships between mating system, spatial behaviour, and genetic variation in ungulates, with special reference to European cervids
}

\author{
Marco APOLLONIO
}

\begin{abstract}
Apollonio M. 1998. Relationships between mating system, spatial behaviour, and genetic variation in ungulates, with special reference to European cervids. [In: Ecological genetics in mammals III. G. B. Hartl and J. Markowski, eds]. Acta Theriologica, Suppl. 5: 155-162.

The relationship between mating system and genetic variation in ungulates is examined in the light of behavioural and ecological data on selected species. Overall results confirm that a model based on increasing genetic variability with decreasing degree of polygyny is realistic. However, this generalization presents a number of difficulties due to (i) species with populations that adopt different mating systems (ii) populations with males adopting different mating strategies (iii) species with similar mating systems but different rut duration, and these must be considered. In conclusion, the difficulty in conducting this kind of comparative studies and the need to restrict comparisons to rather closely related taxa (ie within families) where sound behavioural and ecological data are available are evidenced.
\end{abstract}

Dipartimento di Etologia, Ecologia, Evoluzione, Università di Pisa, via Volta 6, 56126 Pisa, Italy

Key words: mating system, genetic variation, ungulates

\section{Introduction}

The general concept of the influence of the effective population size $\left(N_{e}\right)$ on the genetic variability of a population can be examined by a detailed investigation of the different variables that have an influence on this parameter. One of these variables is represented by the number of males effectively participating in reproduction: if the number decreases, and, thus, the variance in reproductive success among males increases, we expect the genetic variability of a population to decrease. This idea was already examined by Apollonio and Hartl (1993) for some selected families of mammals, such as the Cervidae, the Bovidae, and the Canidae. They tested the hypothesis that the degree of polygyny of a mating system is negatively correlated with genetic variability within populations/species. In so doing, the potential effect of the extent of female monopolization by males on $N_{e}$, and, thus, on the genetic variability of the population, was evaluated. The results were consistent with the prediction stated above for cervids. This was less true for bovids, and in general some ambiguous results were observed. Taking into 
account some parameters of the more common ungulate mating systems and their possible influence on the degree of polygyny, the present analysis aims at examining the difficulties associated with testing the influence of mating systems on genetic variation. In particular, the role of variability in the mating behaviour at the level of the species, the population, and the individual is evaluated.

\section{Characteristics of mating systems}

Data on different mating systems and their characteristics were extracted from the literature or obtained from unpublished results from different study areas that will be mentioned in the text. The following mating system parameters will be considered:

1. Breeding party size: the number of females that a male can monopolize at once.

2. Theoretical male breeding opportunities: the number of females a male can monopolize in each breeding season.

3. Effective male breeding opportunities: the number of females a male was observed to copulate with in a breeding season.

4. Standardized variance of male mating success, $I m=\sigma^{2} / X^{2}$, where $\sigma^{2}$ is the variance of mole mating success within a group of males and $X$ is the number of individuals of the group (Arnold and Wade 1984a, b).

As in some cases exact data on these parameters are lacking, their values will be calculated on the basis of empirical results obtained from field studies. The four different mating systems are defined as follows: Lekking $(\mathrm{L})$ - there are aggregations of male reproductive territories containing no resources apart from the males. Females are free to move among different territories whereas males are confined to their territories. Harem defence $(\mathrm{H})$ - males defend groups of females and move with them. They do not have a spatial reference for dominance but just defend the females and wait for them to come into estrus. Resource territory defence (T) males defend spatially separated territories containing a certain amount of resources for females. The quality and quantity of these resources may have a strong influence on male mating success. Roving $(R)$ - males follow single females testing whether they are close to estrus. If this is the case, males try to defend the respective female until it accepts copulation. Then they look for other females.

\section{The model and the case studies}

In a general approach it can be hypothesized that the degree of polygyny of the mating systems we have considered is different, and that its extent will increase from roving to lekking (Fig. 1).

Lekking. For this mating system the example species selected is fallow deer Dama dama. In October males set up territories in clusters along routes of females; estrous females visit these territories and wait until they are mated. Most females copulate only once per mating season. This means that the number of copulations 


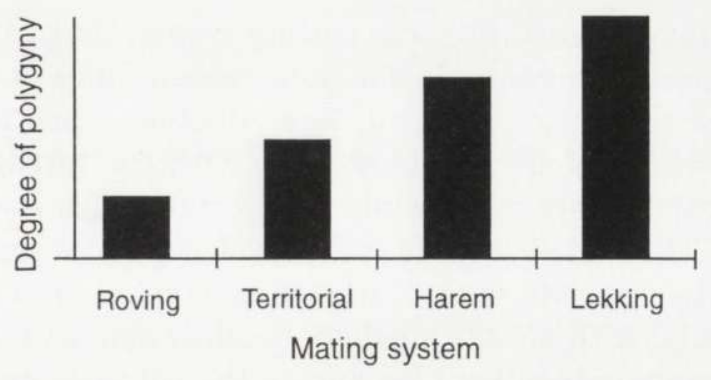

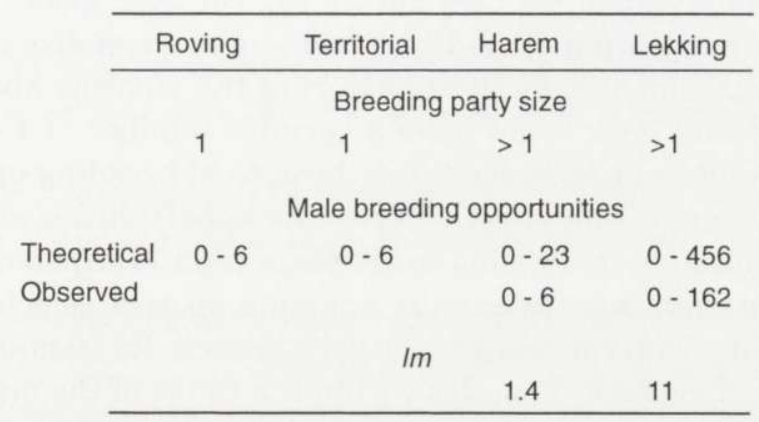

Fig. 1. Model illustrating the relationship between the mating system adopted and the degree of polygyny in ungulates, and data on mating system characteristics relevant for the model.

is a reliable estimate of male mating success. The highest number of copulations estimated (taking twice the number of copulations observed only during daylight) in a lek for a whole breeding season was 456 . The highest number of copulations estimated the same way for one male and one season was 162 . The standardized variance in lifetime male reproductive success, calculated for all males older than four years seen on the lek (either territorial or not), was approximately 11 (cf Apollonio et al. 1989, 1990, 1994).

Harem defence. For this mating system the example species selected is red deer Cervus elaphus. In autumn males defend herds of females which can be both estrous and anestrous. They move with the herd and have access to any estrous female. Fighting success is decisive to have a high reproductive success. The highest number of females recorded in a harem was 23 . The highest number of copulations estimated in a season (taking into account the time spent by each female in a stag harem and the parturition date) for one stag was 6 . The standardized variance in lifetime male reproductive success, calculated for all males of the population (either harem holding or not) older than five years was about 1.2 (Clutton-Brock et al. 1982, Clutton-Brock 1987). These results should be considered with some caution because of the findings obtained by Pemberton et al. (1992) who showed through a genetic analysis that the mating success of successful males was underestimated and that of unsuccessful males was overestimated in behavioural observations. So probably real $\mathrm{Im}$-values are higher. 
Resource territory defence. For this mating system the example species selected is roe deer Capreolus capreolus. In forested areas, males of this species begin to establish resource territories in April. Reproduction takes place in July/August, and the females whose home ranges overlap with the territory of a male can be courted and mated by this male. Only territorial males have access to females (Ellenberg 1978). The male is able to court one female at a time. Males can become territorial after their second year of life. In a forested area (Foreste Casentinesi National Park, Italy) with an intermediate roe deer density (about 15 deer/100 ha), the mean home range size of females during the rut was about 30 ha $(n=12)$, at the same time, territorial males had territories of a mean size of 40 ha $(n=10)$. Taking into account that female density during the rut was about 8 individuals /100 ha, one territorial buck could have a variable number of 1-8 females on his territory, and this interval represents his theoretical breeding opportunities. It is quite difficult to evaluate the effective breeding opportunities and the $\mathrm{Im}$ as this species is hard to observe in forested areas (data from M. Apollonio, unpubl.).

Roving. For this mating system the example species selected is alpine ibex Capra ibex. During the rut males actively search for females, testing each unguarded female they meet. Females within the range of the male can be estrous and anestrous. Males can court one estrous female at a time. Males become dominant in courtships once they are 10 years or older. In Gran Paradiso National Park, western Alps, Italy, the home range of an adult male during the rut is about 30 ha $(n=10)$ with a high variance. The mean overlap among the home ranges of these males was $33 \%$ with one extreme case of $94 \%$. Female density in the rutting area was about 20 females/100 ha. This means that a male can meet a maximum of 6-7 females in its home range, provided that the spatial position of females is as stable as it appeared in preliminary observations (Apollonio et al. 1997, Bassano et al. 1997).

Altogether these results give a picture that is quite compatible with the general model (Fig. 1).

\section{Problems concerning the application of the general model}

Species with populations that adopt different mating systems

The significance of the mating system in determining some level of skew in male mating success in a species may be best evaluated by comparisons of $\mathrm{Im}$ among populations of the same species, which have adopted different mating systems. Furthermore, the correct identification of the mating system adopted by one population of a species showing some polymorphism in breeding behaviour is crucial for analyses on the relationship between mating system and genetic variability.

Lekking: the fallow deer is a good example of behavioural polymorphism. This species can adopt almost all mating systems known for ungulates (Langbein and Thirgood 1989). It is an intriguing question whether the high variance in male mating success recorded for lekking populations is due to that particular mating 
system or is a general characteristic of the species. In a comparison of Im-values from two leks with those of a population showing a non-territorial mating system based on dominance Apollonio et al. (1994) showed that the respective estimates were quite similar. Therefore it seems that in the fallow deer low genetic variability can be connected not only with the occurrence of lekking, but with a more general tendency to develop a high skew in fitness among males, irrespective of the mating system adopted. Harem defence: for a long time red deer was considered the best example of a species displaying harem defence. However, recently Carranza et al. (1990) showed that, in an area characterized by strong heterogeneity in resource distribution, males may defend territories and have access to females visiting them for food. There is no data on Im available of this population for a comparison with the respective values found in more common situations, but, as in the previous example on fallow deer, we can ask if $I m$ can be expected to be different or not. Moreover, we can ask in how many populations, previously thought to show harem defence simply by default, males were actually territorial or showed a combination of the two mating systems. Resource territory defence: Roe deer is known to adopt different mating systems in relation to environmental conditions. In forested areas, resource territory defence is adopted in response to a predictable resource distribution. On the contrary, where resource distribution is not predictable, eg in agricultural areas and in montaneous areas close to the climatic tree line, the patterns of male territories are less stable or even absent. This leads to the adoption of different mating systems in the latter cases, often characterized by roving males looking for females to copulate with. To evaluate the impact of these differences on genetic variability, Kurt et al. (1993) compared two samples of roe deer populations with the different mating systems: no differences in the values of $P$ and $H$ were found even if $F_{I S}$ was significantly more positive in the territorial group.

\section{Populations with males adopting different mating strategies}

The presence of individuals adopting alternative mating strategies in a population raises the issue of their respective contribution, in terms of young fathered, to the genetic composition of the population. Knowledge of the reproductive success associated with the alternative mating strategies is important for evaluating the extent of the variation introduced in a model based on the adoption of a simple mating system by a species.

Lekking: fallow deer can show an intrapopulation polymorphism in reproductive behaviour. In lekking populations, alternative mating strategies may be adopted by males (Clutton-Brock et al. 1988, Apollonio et al. 1992). Such alternative strategies can be either resource defence or single territory defence. These are chosen by inferior competitors that cannot sustain the high intermale competition at the leks. In both studies mentioned above, males adopting strategies different from lekking seemed to have a quite limited reproductive success, and therefore to contribute only scarcely to the general pattern of the population $I m$ and, thus, to genetic variability. Harem defence: young red deer may adopt a kleptogamist 
strategy; they try to intercept females belonging to the harem of an adult male and to copulate with them (Clutton Brock et al. 1982). Taking into account the results of Pemberton et al. (1992), who emphasized the skew of male mating success in favour of a few very successful males by analysing paternity data in a red deer population, the reproductive success of this strategy must be very scarce. Resource territory defence: In a very heterogeneous area that includes habitats with opposite characteristics regarding resource distribution, male roe deer can adopt different mating strategies. The Maremma Regional Park, Italy, is a densely wooded area surrounded by cultivated fields. In this area some males, during spring and summer, can behave territorial, defending small territories in which the longest movements are of about $1 \mathrm{~km}$. Other males can roam widely, covering distances up to $12 \mathrm{~km}$ and showing no attitude to set up territories. No information is available on the reproductive success of these two categories of adult males (M. Apollonio, unpubl.). Roving: in ibex it is possible to observe an age dependent alternative mating strategy. Young males that can not compete with fully grown up ones in static courtship try to have access to females following them in fast chases trough deep ravines. In so doing, they are favoured by their small body size, being close to that of the females. Once they reach a female, they try to copulate grasping her when she is running away (Apollonio et al. 1997). The same alternative strategy was described by Hogg (1988) for bighorn sheep (Ovis canadensis). We have no data on reproductive success of these young males in ibex, but some success for young rams adopting this coursing strategy was found by the aforementioned author in bighorn sheep (Hogg and Forbes 1997).

Species with similar mating systems with different rut duration

Rut duration may be an important factor in defining the benefits and costs of a mating system or of a mating strategy. The amount of time a male should spend engaged in an intense courting activity may have an obvious effect on the total costs for its energetic budget and, ultimately, on its survival. This is the reason why it is difficult to compare data that take into account both tropical and temperate ungulate species. In the former, a lack of strong seasonality may induce a prolonged breeding activity which is completely different from the short breeding time of ungulates living in temperate ecosystems. Lekking: a good example of the differences mentioned above is given by the evaluation of benefits and costs connected to the different mating strategies in two lekking species: the temperate fallow deer and the tropical topi (Damaliscus korrigum). In the first case lekking is obviously the most successful strategy, and males adopting it have high seasonal and lifetime breeding success. On the contrary, in the topi the long duration of the breeding season makes it impossible for a male to defend a lek territory for the whole breeding season. Males are just able to sustain the high costs for a while and then give up and come back to their bachelor herds. On the contrary, males defending single territories can sustain their ownership throughout the breeding season having, in the long run, far better chances to improve their fitness. 
In this case the best competitors can be found in resource territories and not on the lek (Gosling and Petrie 1990).

\section{Conclusions}

From the argunents presented here it becomes obvious how difficult it can be to evaluate the relationship between genetic variability and the mating system, ie a single behavioural characteristic, even for a group of closely related mammalian species. This may be due to the importance of the environmental component in promoting the adoption of one or the other mating system by a population (Emlen and Oring 1977), which may cause serious problems in comparative investigations. However, at least in cervids and partially also in bovids, it seems to be possible to demonstrate a negative relationship between the degree of polygyny and values of genetic variability (Apollonio and Hartl 1993). This may seem surprising considering the additional social and life history component that can influence population structure and genetic variability in ungulate populations (Chesser et al. 1993, Scribner 1993). Another element that comes out quite clearly is the extreme difficulty in applying approaches that try to link genetic variability and ecological or behavioural characteristics across members of higher taxa, such as classes or subphyla (Nevo 1983, Nevo et al. 1984). The huge amount of biological variability present within larger taxa and the consequent impossibility of meaningful wide generalizations militates against these attempts.

My review of ideas and problems about genetic variability and mating systems clearly points out the need for long-term behavioural and ecological studies on populations with marked individuals conducted with both observational and molecular methods (Pemberton and Slate 1998), to properly evaluate important parameters such as the individual mating success and the level of relatedness among groups or individuals. Only a relevant effort towards interdisciplinary research can guarantee further progress in the study of correlations between genetic variability and behavioural or ecological characteristics of mammalian species.

\section{References}

Apollonio M., Festa-Bianchet M. and Mari F. 1989. Correlates of copulatory success in a fallow deer lek. Behavioural Ecology and Sociobiology 25: 89-97.

Apollonio M., Festa-Bianchet M., Mari F. and Riva M. 1990. Site-specific asymmetries in male copulatory success in a fallow deer lek. Animal Behaviour 39: 205-212.

Apollonio M., Festa-Bianchet M., Mari F., Mattioli S. and Sarno B. 1992. To lek or not to lek: mating strategies of male fallow deer. Behavioral Ecology 3: 25-31.

Apollonio M. and Hartl G. 1993. Are biochemical-genetic variation and mating systems related in large mammals? [In: Ecological genetics in mammals. G.B. Hartl and J. Markowski, eds]. Acta Theriologica 38, Suppl. 2: 175-185.

Apollonio M., Giannelli S. and Rossi I. 1994. Variance in male mating success in Cervids: the role of mating systems vs species differences. Proceedings of the 16 Meeting of the Italian Society for the study of animal behaviour. Bollettino di Zoologia 61 Suppl.: 57. 
Apollonio M., Mauri L. and Bassano B. 1997. Reproductive strategies of male alpine ibex in Gran Paradiso National Park. 2nd World Conference on Mountain Ungulates. Abstract volume: 12.

Arnold S. J. and Wade M. J. 1984a. On the measurement of natural and sexual selection: theory. Evolution 38: 709-719.

Arnold S. J. and Wade M. J. 1984b. On the measurement of natural and sexual selection: applications. Evolution 38: 720-734.

Bassano B., Grignoglio S., Mongiov M., Bethaz M., Parrini F., Gualazzi S., Peracino A. and Apollonio M. 1997. Spatial behaviour of male alpine ibex in Gran Paradiso National Park. 2nd World Conference on Mountain Ungulates. Abstract volume: 51.

Carranza J., Alvarez F. and Redondo T. 1990. Territoriality as a mating strategy in red deer. Animal Behaviour 40: 79-88.

Chesser R. K., Sugg D. W., Rhodes E., Jr, Novak J. M. and Smith M. H. 1993. Evolution of mammalian social structure. [In: Ecological genetics in mammals. G. B. Hartl and J. Markowski, eds]. Acta Theriologica 38, Suppl. 2: 163-174.

Clutton-Brock T. H., Guinness F. E. and Albon S. D. 1982. Red deer - Behaviour and ecology of two sexes. Edinburgh University Press, Edinburgh: 1-378.

Clutton-Brock T. H. 1987. Sexual selection in the Cervidae. [In: Biology and management of the Cervidae. C. M. Wemmer, ed]. Smithsonian Institution Press, Washington D.C.: 110-122.

Clutton-Brock T. H., Albon S. D. and Guinness F. E. 1988. Reproductive success in male and female red deer. [In: Reproductive success. T. H. Clutton-Brock, ed]. Chicago University Press, Chicago: $325-343$.

Ellenberg H. 1978. Zur Populationsökologie des Rehes (Capreolus capreolus L. Cervidae) in Mitteleuropa. Spixiana, Suppl. 2: 1-212.

Emlen S. T. and Oring L. W. 1977. Ecology, sexual selection, and the evolution of mating systems. Science 197: 215-223.

Gosling L. M. and Petrie M. 1990. Lekking in topi: a consequence of satellite behaviour by small males at hotspots. Animal Behaviour 40: 272-287.

Hogg J. T. 1988. Copulatory tactics in relation to sperm competition in Rocky Mountain bighorn sheep. Behavioural Ecology and Sociobiology 22: 49-59.

Hogg J. T. and Forbes S. H. 1997. Mating in bighorn sheep: frequent male reproduction via a high-risk unconventional tactic. Behavioural Ecology and Sociobiology 41: 33-48.

Kurt F., Hartl G. B. and Völkl F. 1993. Breeding strategies and genetic variation in European roe deer Capreolus capreolus populations. [In: Ecological genetics in mammals. G. B. Hartl and J. Markowski, eds]. Acta Theriologica 38, Suppl. 2: 187-194.

Langbein J. and Thirgood S. J. 1989. Variation in mating system of fallow deer (Dama dama) in relation to ecology. Ethology 83: 195-214.

Nevo E. 1983. Population genetics and ecology: the interface. [In: Evolution from molecules to men. D. S. Bendall, ed]. Cambridge University Press, Cambridge: 287-321.

Nevo E., Beiles A. and Ben-Shlomo R. 1984. The evolutionary significance of genetic diversity: ecological, demographic and life history correlates. [In: Evolutionary dynamics of genetic diversity. G. S. Mani, ed]. Lecture Notes in Biomathematics, Springer Verlag, Berlin: 13-213.

Pemberton J. M., Albon S. D., Guinness F. E., Clutton-Brock T. H. and Dover G. A. 1992. Behavioral estimates of male mating success tested by DNA fingerprinting in a polygynous mammal. Behavioral Ecology 3: 66-75.

Pemberton J. M. and Slate J. 1998. Genetic studies of wild deer populations: a technical revolution. [In: Recent developments in deer biology. T. A. Milne, ed]. Proceedings of the third international congress on the biology of deer. Macaulay Land Use Research Institute Craigiebuckler, Aberdeen and Moredun Research Institute, Edinburgh, U.K.: 64-72.

Scribner K. T. 1993. Conservation genetics of managed ungulate populations. [In: Ecological genetics in mammals. G. B. Hartl and J. Markowski, eds]. Acta Theriologica 38, Suppl. 2: 89-101.

Received 23 March 1998, accepted 30 April 1998. 